\title{
Evaluation of Greenhouse Gas Emissions from and the Economic Efficiency of the "Hita City Biomass Recycle Center"
}

\author{
Takanobu Hamasaka \\ Department of Agricultural and Resource Economics, Faculty of Agriculture, Kyushu University, Fukuoka 812-8581, Japan
}

\begin{abstract}
Many biomass recycling facilities have been established in Japan, but its environmental efficiencies have been studied little. MIC has stated that these facilities do not work as well as expected. The environmental and economic efficiencies of a biomass recycling center (representative of other recycling facilities) in Hita city are assessed here. The center was built to decrease the amount of waste needing to be disposed of, and is unusual in that it generates electricity using the methane produced. Electricity produced from biomass sells at a higher price than electricity sold by electricity companies in Japan, and this strongly affects the recycling center operation. The environmental efficiency of the recycling center was assessed using a lifecycle assessment method, and the economic efficiency was assessed from the amounts of greenhouse gases emitted and the running costs. As the result, it was clear that the recycling center emits about $20 \%$ of the greenhouse gases that were previously emitted. Treating biomass at the recycling center costs 1,356 yen per ton of biomass throughout the year. In conclusion, the recycling center decreases the environmental footprint of Hita city. The cost of decreasing greenhouse gas emissions is about 1,400 yen per ton of biomass.
\end{abstract}

Key words: Life cycle assessment, greenhouse gas, methane fermentation apparatus.

\section{Introduction}

The stock-raising industry in Japan has developed dramatically since 1960 , and there were more than ten million breeding domestic pigs in Japan in 1981. Stock raising is a particularly important industry in Kyushu, which is an island west of the main island of Japan. There are about $3,086,720$ pigs (about $30 \%$ of all of the pigs in Japan) in Kyushu. About $7 \times 106 \mathrm{t}$ of pig manure is produced every year in Kyushu even though Kyushu makes up only $10 \%$ of the total land area of Japan [1, 2]. Japanese livestock farmers have been unsure how to deal with livestock manure since the Japanese government enacted a law on the disposal of livestock manure [3] in 1999. Toyonaga et al. [4] measured air pollution in the Kyushu and Yamaguchi areas over a number of years and found that dichloromethane has a tendency to increase.

Corresponding author: Takanobu Hamasaka, Ph.D., research field: environmental economics. E-mail: yuramomo2000@yahoo.co.jp.
Environmental problems, such as water quality and air pollution problems, caused Hita city, in Ohita prefecture, to build a recycling center to allow livestock manure to be treated and used in a beneficial way. The recycling center is also expected to decrease the amount of municipal waste that needs to be incinerated. This is because Hita city must respond to the environmental problems caused by the increasing amount of waste that is produced in the city [5].

"Hita city biomass recycle center" in Hita city contains a methane fermentation system for treating wet biomass. Such systems are popular in Japan. The recycling center has received government subsidies for recycling wet biomass since 2006. However, the government programs for recycling biomass have progressed slowly for the following reasons. The Japanese Institute of Energy Economics [6] found that there are economic problems associated with recycling biomass. For example, many methane fermentation facilities do not work in accordance with plans. The 
Japanese National Agriculture and Food Research Organizationed [7] stated that constructing a methane fermentation facility would cost more than 450 million dollars. The Japanese Institute of Energy Economicsed [6] stated that a way of solving the economic problems associated with recycling biomass would be improving the economic efficiencies of methane fermentation facilities.

Greenhouse Gas (GHG) emissions from the biomass recycling center (later simply called the recycling center) in Hita city were quantified and the economic efficiency of the recycling center was analyzed in the study described here. The results were used to demonstrate the superiority of the recycling center over the conventional methods that are available for disposing of biomass (in an incineration plant and in a sewage treatment facility) in Hita city.

Lifecycle Assessment (LCA) was performed to examine GHG emissions $[8,9]$. The environment and the economic efficiency of the recycling center were made clear by measuring the GHG emissions and the cost of operating the recycling center. The results were compared with the results for a municipal waste disposal plant and a sewage treatment facility in Hita city.

Many studies of methane fermentation have been performed from the environmental engineering and agricultural technology perspectives [10], but economic aspects of methane fermentation have not been considered in these studies.

This paper showed the economic efficiency of methane fermentation. Therefore, government agencies and private companies can make use of this paper in the development of policy guidelines when decisions are made about the introduction of methane fermentation systems. The results are also expected to encourage the recycling of biomass.

\section{Method}

\subsection{Setting the System Boundaries}

The boundaries of the system used in the LCA analysis are shown in Fig. 1. The LCA analysis was performed using only the GHG emissions from the recycling center in Hita city in 2011. The GHG emissions caused by the construction and dismantling of the center and by using the liquid fertilizer produced by the recycling center were not included.

The analysis was focused on the transportation of the biomass, the use of electricity, the use of municipal waste incineration facilities, the use of wastewater processing facilities, and the production and transportation of subsidiary materials. The subsidiary materials that were considered were antifoaming agents, caustic soda, desulfurizing agents, engine oil, grease, methanol, polymeric flocculating agents, slaked lime, SP super-clean EX-10 and sulfuric acid.

The transportation of biomass included transportation involved in the liquid fertilizer and compost production processes. The GHG emissions produced by the administrative and other ancillary departments of the recycling center were excluded from the analysis because these GHG emissions bear no relation to recycling biomass.

The LCA analysis that was performed was focused on the "greenhouse effect". Six gases $\left(\mathrm{CH}_{4}, \mathrm{CO}_{2}\right.$, $\mathrm{HFC}_{8}, \mathrm{~N}_{2} \mathrm{O}, \mathrm{PFC}_{8}$ and $\mathrm{SF}_{6}$ ) related to global warming were evaluated. The amounts of these six gases emitted were converted into $\mathrm{CO}_{2}$ equivalents $\left(\mathrm{CO}_{2}\right.$ eq. $)$ using previously published factors [11].

\subsection{Inventory Analysis in the LCA}

2.2.1 Amounts of Biomass Collected and the Biomass Transportation Distances

The amounts of biomass collected were estimated from the available biomass collection records which were gotten in field work. In total, 6,322 $\mathrm{t}$ of municipal waste, $4,006 \mathrm{t}$ of clear shochu liquor (a distillery by-product), 7,470 $\mathrm{t}$ of pig slurry (a mixture of feces and urine) and 1,717 $\mathrm{t}$ of agricultural waste were collected. 


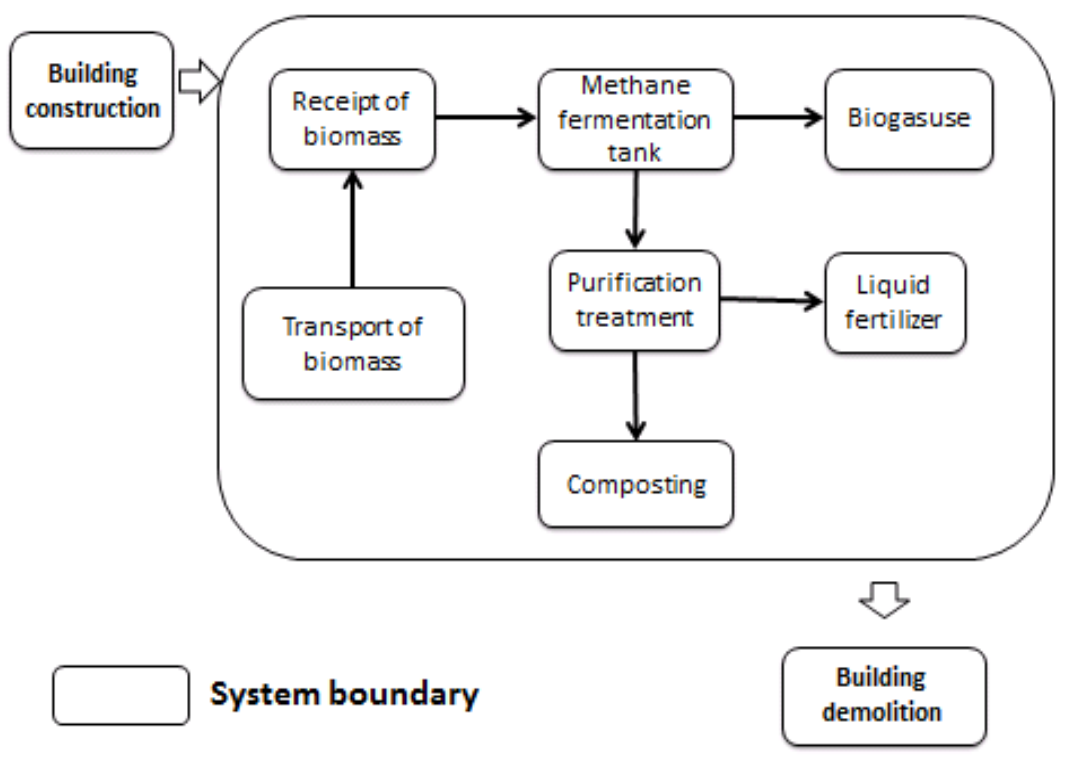

Fig. 1 Boundaries of the system used in the life cycle assessment.

The distances the waste products were transported were estimated from the available transportation records which were gotten from field work.

2.2.2 Production and Transportation of Subsidiary Materials

The subsidiary materials mentioned above were used when dealing with the biomass. The amounts of the subsidiary materials used were estimated from the relevant records. The distances the subsidiary materials were transported were estimated by performing a field survey and by using MapFan [12] and NAVI Time [13] web service.

2.2.3 Waste Produced Dealing with Biomass and during Disposal

About 1,433 $\mathrm{t}$ of combustible waste was removed from the municipal waste that was collected. About $19,670 \mathrm{~m}^{3}$ of dirty water was emitted to the wastewater system by the recycling center.

The distance from the recycling center to the waste treatment site was estimated using MapFan. The GHG emissions produced dealing with the biomass included the GHG emissions produced transporting the waste to the waste treatment sites and running the waste treatment sites.
2.2.4 Effects of Producing Liquid Fertilizer and Compost from Biomass

The amount of liquid fertilizer and compost that was produced was divided by the amount of biomass collected. A total of $0.14 \mathrm{t}$ of liquid fertilizer and compost was produced from $1 \mathrm{t}$ of biomass.

2.2.5 Amount of Power Generated from Methane

About $1,926,000 \mathrm{kWh}$ of power was generated by turbines turned by the methane that was produced. Operating the recycling center required $1,563,000$ $\mathrm{kWh}$. The recycling center therefore produced $363,000 \mathrm{kWh}$ in 2011.

\section{Results and Discussion}

\subsection{Impact Assessment within the System Boundaries}

The amount of GHGs emitted per unit of biomass collected was estimated by compiling a lifecycle inventory. GHG emissions during each process within the system boundaries were first assessed from field measurements and data reported by workers. The GHG emission data were added together, and then the total amount of GHGs emitted was divided by the amount of biomass collected to give the amount of GHGs emitted per ton of biomass collected. 
3.1.1 Amounts of GHGs Emitted Transporting Materials

The amounts of GHGs emitted transporting the materials are shown in Table 1. Transporting municipal waste caused $40,788 \mathrm{~kg} \mathrm{CO}_{2}$ eq. to be emitted, $72.5 \%$ of all of the GHGs emitted through transporting materials. The amount of GHGs emitted transporting municipal waste was high because the recycling center had to collect the municipal waste directly from the households and companies that produced the waste.

3.1.2 Amounts of GHGs Emitted Producing the Subsidiary Materials

The amounts of GHGs emitted producing subsidiary materials are shown in Table 2. The production of methanol was found to cause a particularly large amount of GHGs to be emitted (194,670 kg $\mathrm{CO}_{2}$ eq., $60.2 \%$ of all of the GHGs emitted producing the secondary materials). This was because more $\mathrm{CO}_{2}$ was emitted per unit of methanol consumed than per unit of the other subsidiary materials consumed and because the recycling center used large amounts of methanol to control the release of offensive odors. It is not absolutely essential to remove offensive odors when a methane fermentation system is used, so, it would be possible to decrease the amount of GHGs emitted by using a subsidiary material other than methanol.

3.1.3 Total Amounts of GHGs Emitted in All of the Processes

The amounts of GHGs emitted in all of the processes are shown in Table 3. The amount of GHGs emitted through transportation is the sum shown in Table 1. The amount of GHGs emitted producing subsidiary materials is the sum shown in Table 2 . The amounts of GHGs emitted through the use of electricity, a municipal waste incinerator, water, and the wastewater system were taken from "MiLCA", which is the software system that was used to perform the LCA.

It can be seen from Table 3 that more GHGs were emitted through using the municipal waste incinerator than through any other process. Using the municipal waste incinerator caused $1,831,131 \mathrm{~kg} \mathrm{CO}_{2}$ eq. to be emitted, $78.0 \%$ of the GHGs emitted through the whole system. The recycling center was able to separate impurities from the biomass collected, and a total of $1,435 \mathrm{t}(22.7 \%$ of all of the biomass collected $)$ was able to be separated in 2011. Municipal waste is collected in bags in Hita city. In contrast, To [14] reported that impurities contribute only $3.0 \%$ of all of the biomass collected in Oki city, where biomass is

Table 1 Amounts of greenhouse gases emitted through transportation.

\begin{tabular}{ll}
\hline Material being transported & $\begin{array}{l}\text { Amount of greenhouse gases emitted } \\
\left(\mathrm{kg} \mathrm{CO}_{2} \text { equivalent }\right)\end{array}$ \\
\hline Agricultural waste & 1,271 \\
Antifoaming agents & 50 \\
Caustic soda & 875 \\
Desulfurizing agents & 31 \\
Flocculants & 22 \\
Grease and engine oil & 0 \\
Methanol & 2,205 \\
Municipal waste & 40,788 \\
Pig slurry & 7,228 \\
Shochu distillery waste & 1,985 \\
Slaked lime & 184 \\
Sulfuric acid & 1,488 \\
SP super-clean EX-10 & 61 \\
Total & 56,188 \\
\hline
\end{tabular}



"Hita City Biomass Recycle Center"

Table 2 Amounts of greenhouse gases emitted producing secondary materials.

\begin{tabular}{ll}
\hline Secondary material & $\begin{array}{l}\text { Amount of greenhouse gases emitted } \\
\left(\mathrm{kg} \mathrm{CO}_{2} \text { equivalent }\right)\end{array}$ \\
\hline Antifoaming agents & 27,870 \\
Caustic soda & 65,850 \\
Desulfurizing agents & 11,274 \\
Flocculants & 4,556 \\
Grease and engine oil & 1,062 \\
Methanol & 194,670 \\
Slaked lime & 10,994 \\
SP super-clean EX-10 & 2,398 \\
Sulfuric acid & 4,955 \\
Total & 323,629 \\
\hline
\end{tabular}

Table 3 Amounts of greenhouse gases emitted during all of the processes.

\begin{tabular}{ll}
\hline Process & $\begin{array}{l}\text { Amount of greenhouse gases emitted } \\
\left(\mathrm{kg} \mathrm{CO}_{2} \text { equivalent }\right)\end{array}$ \\
\hline Electricity used & 125,236 \\
Incineration & $1,831,131$ \\
Production of secondary materials & 323,627 \\
Transportation & 56,188 \\
Transportation of non-biomass waste & 3,111 \\
Wastewater treatment & 10,017 \\
Water used & 59 \\
Total & $2,349,369$ \\
\hline
\end{tabular}

collected in plastic buckets. The method of municipal waste and biomass collection clearly affects the amount of impurities that needs to be removed.

In total, the amount of GHGs emitted per ton of biomass collected was found to be $120.39 \mathrm{~kg} \mathrm{CO}$ eq. $\cdot \mathrm{t}^{-1}$.

\subsection{Economic Evaluation of the Recycling Center in Hita City}

The total costs incurred by the recycling center in 2011 are shown in Table 4. The costs were measured or reported by workers. "Labor costs" are the salaries of the regular staff, and "wages" are the wages paid to part-time staff. "Expenditure on supplies" is the cost of operating the recycling center, including, for example, fuel costs and electricity costs. "Commissioning expenses" include the cost of transporting municipal waste. The costs involved in transporting shochu distillery waste, pig manure, and agricultural waste were not included because they were transported by external organizations by paying money. The recycling center cost $900,000,000$ yen to build, and the depreciation of the building was calculated using the linear depreciation method, using a 30 y depreciation time and a 10\% salvage rate.

The depreciation costs do not include the depreciation of vehicles used to transport the biomass because the recycling center used contractors to transport the biomass. The costs of transporting the biomass are contained in the "rent" costs.

\subsection{Income of the Recycling Center}

The recycling center had an income of 52,717,000 yen in 2011. The details are shown in Table 5.

\subsection{Comparison of the Recycling Center with a} Municipal Waste Disposal Plant and A Wastewater Treatment Plant

Biomass was disposed of by a municipal waste incinerator and a wastewater treatment plant before the recycling center was built. The amounts of GHGs that were emitted when these plants treated the 
Table 4 Costs in 2011.

\begin{tabular}{ll}
\hline Cost type & Cost $(1,000$ yen $)$ \\
\hline Commissioning expenses & 49,920 \\
Depreciation & 27,000 \\
Expenditure on supplies & 32,399 \\
Expenses for government business & 118 \\
Fittings and appliances & 2,310 \\
Labor costs & 16,495 \\
Rent & 4,515 \\
Service charges & 1,050 \\
Subsidies & 10 \\
Travel costs & 193 \\
Wages & 1,613 \\
Total & 135,623 \\
\hline
\end{tabular}

Table 5 Income in 2011.

\begin{tabular}{ll}
\hline Income type & Income $(1,000$ yen $)$ \\
\hline Compost sold & 871 \\
Electricity sold & 2,822 \\
Municipal waste disposal fees & 41,415 \\
Others & 5 \\
Pig slurry disposal fees & 4,514 \\
Tradable "green certificates" & 2,462 \\
Visit fees & 628 \\
Total & 52,717 \\
\hline
\end{tabular}

biomass produced are shown in Table 6. It was assumed that municipal waste and shochu distillery waste would be burned and that pig slurry would be treated in the wastewater treatment plant. Pig slurry was assumed to have a specific gravity of 1.0 .

The total amount of GHGs emitted from the municipal waste incinerator and the wastewater treatment plant was found to be $13,638,331 \mathrm{~kg} \mathrm{CO}_{2}$ eq., and 19,514 t of biomass was collected. Therefore, the amount of GHGs emitted per $1 \mathrm{t}$ of biomass collected was $698.80 \mathrm{~kg} \mathrm{CO}$ eq. $\mathrm{t}^{-1}$.

The amount of GHGs emitted per ton of biomass collected was decreased by $578.51 \mathrm{~kg} \mathrm{CO}$ eq. $\mathrm{t}^{-1}$ by introducing the recycling center.

\subsection{Cost Effectiveness of Introducing the Recycling} Center

The cost effectiveness of introducing the recycling center was assessed by subtracting the total amount of
GHGs emitted by the recycling center $(2,349,389 \mathrm{~kg}$ $\mathrm{CO}_{2}$ eq.) from the total amount of GHGs emitted by the municipal waste incinerator and the wastewater treatment plant $\left(13,636,331 \mathrm{~kg} \quad \mathrm{CO}_{2}\right.$ eq.). This calculation showed that the recycling center saved $11,288,962 \mathrm{~kg} \mathrm{CO} 2$ eq. from being produced.

The operating loss (calculated by subtracting the total income shown in Table 5 from the total costs shown in Table 4) of the recycling center in 2011 was $82,906,000$ yen.

The decrease in the amount of GHGs emitted per unit cost achieved by introducing the recycling center was therefore $136 \mathrm{~kg} \mathrm{CO}$ eq. $\mathrm{yen}^{-1}$.

\subsection{Simulation of the Influence of Selling Electricity on GHG Emissions}

\subsubsection{Effects of Selling Green Energy}

\subsubsection{Surplus Power}

More electricity was produced by the recycling center than was used operating the center. The 
Table 6 Amounts of greenhouse gases emitted using biomass disposal methods that were used before the recycling center was built.

\begin{tabular}{lcc}
\hline & Amount of biomass received $(\mathrm{t})$ & $\begin{array}{l}\text { Amount of greenhouse gases emitted } \\
\left(\mathrm{kg} \mathrm{CO}_{2} \text { equivalent) }\right.\end{array}$ \\
\hline Incineration & 10,327 & $13,197,906$ \\
Wastewater treatment & 9,187 & 440,425 \\
Total & 19,514 & $13,638,331$ \\
\hline
\end{tabular}

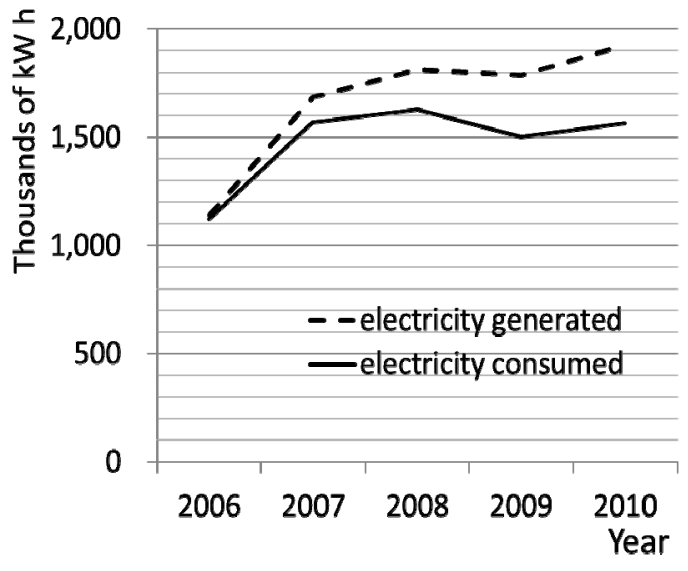

Fig. 2 Electricity generated and consumed between 2006 and 2010.

amounts of electricity generated and consumed between 2006 and 2010 are shown in Fig. 2.

\subsubsection{Income from Selling Green Energy}

The recycling center sold electricity at a "feed-in tariff', which was higher than the cost of buying electricity $[15,16]$. The amounts of electricity generated and consumed between 2006 and 2011 are shown in Table 7.

A profit of $52,845,750$ yen was made in 2010 by selling electricity (calculated using the formula (40.95 yen $(\mathrm{kWh})^{-1} \times 1,926,000 \mathrm{kWh}$ electricity generated) $\left(16.65\right.$ yen $\cdot(\mathrm{kWh})^{-1} \times 1,563,000 \mathrm{kWh}$ electricity consumed).

\subsection{Amount of GHGs Emitted Related to Electricity Sold}

The total amount of GHGs emitted by the recycling center, shown in Table 3, was 3,133,887 kg $\mathrm{CO}_{2}$ eq.. A total of $19,514 \mathrm{t}$ of biomass was collected. Therefore, the amount of GHGs emitted per ton of biomass was $160.59 \mathrm{~kg} \mathrm{CO} \mathrm{eq}^{-1}{ }^{-1}$.

The amount of GHGs emitted $120.39 \mathrm{~kg} \mathrm{CO}$ per ton of biomass when the recycling center used the electricity that was generated. And so, the amount of GHGs emitted per ton of biomass was $40.20 \mathrm{~kg} \mathrm{CO}_{2}$ higher when the electricity was sold than used.

Selling the surplus electricity increased the recycling center's income by $52,845,000$ yen but increased the amount of GHGs emitted by $784,517 \mathrm{~kg}$ $\mathrm{CO}_{2}$ eq..

\section{Conclusion}

The relationship between the amount of GHGs emitted and the cost of treating biomass at the recycling center in Hita city was assessed using LCA. Few similar studies have previously been performed. The LCA results clearly showed that treating biomass at the recycling center caused smaller amounts of GHGs to be emitted than did treating the biomass by incinerating it and sending it to a wastewater treatment plant, as was the case before the recycling center was built.

Incinerating waste was found to have caused $1,831,131 \mathrm{~kg} \mathrm{CO}_{2}$ eq. to have been emitted in 2011 , $78 \%$ of the total amount of GHGs emitted. The residents of Hita city place their waste in plastic bags, so, biomass is mixed with other waste. The plastic bags cannot be recycled, so, the recycling center removes large amounts of combustible waste. It would be possible to decrease the amount of other waste in the waste sent to the recycling center by abandoning this practice in Hita city. For example, the residents of Oki town use plastic buckets to collect their biomass waste, meaning that no plastic bags are present in the biomass that is collected. People in Hita city will need to be educated about the environment to persuade them to adopt the system that is used in Oki town. 
Table 7 Electricity generated and consumed between 2006 and 2011.

\begin{tabular}{lllllll}
\hline Year & 2006 & 2007 & 2008 & 2009 & 2010 & 2011 \\
\hline Electricity generated $(\mathrm{kWh})$ & $1,141,355$ & $1,682,991$ & $1,812,058$ & $1,785,188$ & $1,926,189$ & $1,708,563$ \\
Electricity consumed $(\mathrm{kWh})$ & $1,122,791$ & $1,567,683$ & $1,627,426$ & $1,500,656$ & $1,563,573$ & $1,641,893$ \\
\hline
\end{tabular}

It was found that selling surplus electricity improved the profitability of the recycling center but increased the environmental burden posed by the center. However, even with the recycling center selling surplus electricity, it was better, in terms of GHGs emitted, to treat biomass at the recycling center than in the incinerator and wastewater treatment plant.

It would be possible to decrease the environmental burden posed by treating biomass at the recycling center and to improve the profitability of the center by making changes to some of the recycling center practices. In particular, the potential for using liquid fertilizer effectively must be assessed because little of the liquid fertilizer that is produced by the recycling center is currently used. Large amounts of liquid fertilizer are discharged to the wastewater system. Future research should therefore, be focused on the promotion of the use of liquid fertilizer produced by the recycling center.

\section{References}

[1] Ministry of Agriculture, Forestry and Fisheries. 2015. "Survey of the Numbers of Pigs Reared in Japan." Accessed October 17, 2015. http//:www.e-stat.go. jp/SG1/estat/List.do?bid $=000001024928 \&$ cycode $=0$.

[2] Ministry of Agriculture, Forestry and Fisheries. 2015. "Cattle Statistics for Japan." Accessed October 17, 2015. http//:www.e-stat.go.jp/SG1/estat/List.do?lid=000001127 029.

[3] Ministry of Agriculture, Forestry and Fisheries. 2015. "Act on the Appropriate Treatment and Promotion of Utilization of Livestock Manure." Accessed October 17, 2015. http//:www.maff.go.jp/j/chikusan/kankyo/taisaku/ t_mondai/03_about/.

[4] Muraoka, T., Toyonaga, S., Furusawa, N., Imamura, O., and Kitaoka, H. 2013. "The Influence of Transboundary Air Pollution Per Years of Harmful Air Pollution Material Density in Kyushu and Yamaguchi Area."
Journal of the Environmental Laboratories Association 38: 178-187.

[5] Ministry of Land, Infrastructure, Transport and Tourism. 2015. "River Water Quality in Kyushu." Accessed October 17, 2015. http//:www.mlit.go.jp/river/toukei chousa/kankyo/kankyou/suisitu/.

[6] Institute of Energy Economicsed. 2011. "A Report on Basic Research into the Promotion of New Energy Sources." Accessed October 17, 2015. http//:eneken.ieej. or.jp/report_detail.php?article_info_id $=3763$.

[7] National Agriculture and Food Research Organization. 2006. "Valuation and Design of a System for the Use and Application of Biomass." Accessed October 17, 2015. http//:www.naro.affrc.go.jp/org/nkk/soshiki/soshiki07-shi gen/01 shigen/sekkeitohyouka.html.

[8] Inaba, A. 2005. Lifecycle Assessment Practice. Japan: Environmental Management Association for Industry.

[9] Itsubo, N., Narita, N., and Tahara, K. 2007. Introduction to Lifecycle Assessment. Japan: Environmental Management Association for Industry.

[10] Kai, H., Honda, T., Nakamichi, K., Shinya, Ota, Y., and Yasuhiro, M. I. 2015. "LCA Evaluation of a Recycling Facility Using Shochu Distillery Byproducts." Journal of Life Cycle Assessment 10: 286-287.

[11] Japan Meteorological Agency. 2007. "Intergovernmental Panel on Climate Change (IPCC)." Accessed October 17, 2015. http://www.data.jma.go.jp/cpdinfo/ipcc/ar4/index. html.

[12] MapFan Web Service. 2015. "MapFan." Accessed October 17, 2015. http//:www.mapfan.com.

[13] NAVITime Japan. 2015. "NAVITIME.” Accessed Oct 17, 2015. http//:www.navitime.co.jp.

[14] To, M., and Yabe, M. 2012. "Lifecycle Assessment of Greenhouse Gas Emissions from a Liquid Fertilizer Plant Using Anaerobic Fermentation: A Case Study in Ohki City.” M.S., thesis. Kyushu University.

[15] Agency for Natural Resources and Energy. 2015. "Feed-in Tariff." Accessed October 17, 2015. http//www.enecho.meti.go.jp/category/saving_and_new/s aiene/kaitori/.

[16] Kyushu Electric Power. 2015. "Feed-in Tariff 2015." Accessed October 17, 2015. http://www.kyuden. co.jp/effort_renewable-energy_torikumi.html. 